


\section{Register: de la realización a la activación.}

\section{Register: from realization to activation}

\section{José Manuel Ruiz Martín \& César Augusto Portilla Karolis}

ISSN (imp): 1390-4825

ISSN (e): 2477-9199

\author{
Fecha de recepción: 28/03/18 \\ Fecha de aceptación: 01/05/18
}

\section{Resumen:}

Este artículo presenta el proceso de realización y activación del proyecto multimedia Register, que aborda la discontinuidad entre la inmediatez orgánica de la vida y el mundo simbólico, mediante tecnologías intervenidas. Para ello, se emplearon tecnologías libres y abiertas formadas por dos sistemas interactivos de registro. Con ello, se generó una instalación formada por diferentes ambientes, en los que dos artistas se encuentran inmersos en labores de recolección, clasificación y ficción, empleando diversos géneros, lenguajes y medios, como live art, new media performance y sound design, entre otros. El usuario se enfrenta a la construcción técnica manipulada de su propia imagen y a una experiencia estética en la que se posiciona como espectador y es material fundamental e involuntario de la obra. Así, Register devela el proceso de construcción de la realidad mediada por imágenes esterotipadas en la cultura contemporánea.

\section{Palabras clave:}

Register, Open Sources, Media Art,

experiencia estética, realidad

\section{Abstract:}

This paper shows the process of the Register multimedia project. This project addresses the discontinuity between the organic proximity of life and the symbolic world approached by manipulated technologies. This objective was accomplished using free and open technologies formed by two interactive recording systems. These devices are elements in an installation made up by different environments, where two artists participate collecting, classifying, and functioning. Different categories, languages, and media, such as live art, new media performance and sound design, among others, are part of this installation. On the side of the user, he/she is confronted to a manipulated technical construction of his own image, to an aesthetic experience as well, where he positions himself as witness, and he/she is a fundamental and an involuntary element of artwork. Therefore, Register unveils the process of construction of reality mediated by contemporary culture stereotyped images.

\section{Key Words:}

Register, Open Sources, Media Art, aesthetic experience, reality

\section{Biografía de los autores:}

José Manuel Ruiz Martín. Doctor en Nuevas Prácticas Culturales y Artísticas. Director de Investigación y Posgrado de la Facultad de Artes de la Universidad Central del Ecuador. Ha impartido docencia en grados y posgrados de Espańa y Ecuador, y numerosas ponencias en congresos internacionales de arte y nuevos medios. Autor de los libros Arte, tecnología y sociedad (2018), Register (2017), Electrical Pulses (2016) y El laboratorio actual de Gráfica Digital (2011), y de varias publicaciones y artículos en revistas indexadas sobre laboratorios, centros de creación artística y cultura visual. Como artista multimedia, su obra ha recibido diversos premios y ha formado parte de exposiciones y festivales reconocidos internacionalmente.

César Augusto Portilla Karolis. Doctor en Estética, Ciencias y Tecnologías de las Artes, Universidad París 8 Vincennes Saint Dennis, París, Francia. Artista, investigador y docente de la Facultad de Artes de la Universidad Central del Ecuador. Sus investigaciones exploran la figura del artista como sujeto político, en el sentido de que, a través de su obra, el artista construye tanto su figura de sujeto-artista, así como también el espacio del arte. Ha sido parte de varios colectivos de artistas (PUZ Personal Plástico, Negro Triqueante), aunque su principal labor artística la realiza en Pan Con Cola Producciones (PCCP). 


\section{INTRODUCCIÓN}

El autor no debe interpretar. Pero puede contar por qué y cómo ha escrito. Los llamados escritos de poética no siempre sirven para entender la obra que los ha inspirado, pero permiten entender cómo se resuelve el problema técnico de la producción de una obra (Eco, 1986).

Register es un proyecto artístico site-specific que aborda la discontinuidad entre la inmediatez orgánica de la vida y el mundo simbólico, tal y como ya señalaron autores, desde Hegel (1807) hasta Badiou (2015), Zizek (2012) y Jameson (2009). Se ocupa del proceso que transforma la percepción de la realidad a través de una serie de dispositivos automáticos open source, en el que los artistas -presentes en todo momento- están inmersos en una labor de recolección, clasificación y ficción. El paso de la realidad (la calle) al mundo simbólico (la obra) se realiza a partir del registro de la máquina automática (Ruiz Martín, 2014) -previamente programada por un sistema complejo de algoritmos- (Figura 1), de la labor del register y de las narraciones sonoras ejecutadas por el storyteller. Los dispositivos manipulados e intervenidos aparecen destripados ante el espectador. Register convierte así la galería en un laboratorio de producción que emplea al viandante curioso como muestra azarosa, pero fundamental, en el desarrollo del proyecto.

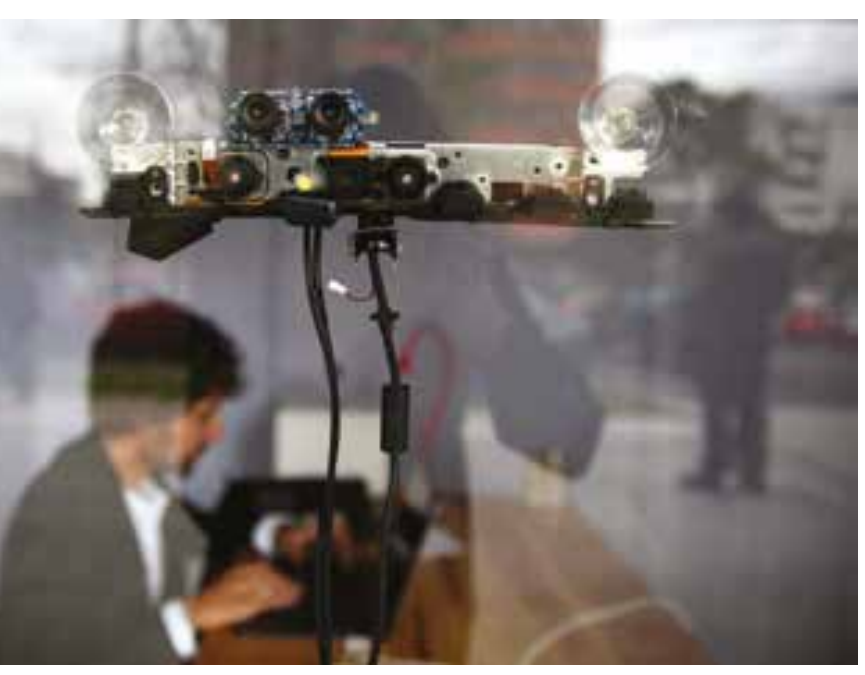

1. Detalle del dispositivo Kinect sobre el escaparate. Fuente: Gabriela Rivadeneira.

En Register, que parte de la polisemia de la palabra inglesa register, se encuentran connotaciones relacionadas con aspectos tanto de la figura del artista como de las prácticas del arte. Primero, el artista que registra es una suerte de interfaz entre el mundo real y lo que se cree de él: un mediador evanescente (Jameson, 2008). Se enrarece el proceso, se instaura la discordancia, lo inatendido, el contraste, mediante la activación de signos producidos a través de dos dispositivos de registro. Estas máquinas han sido substraídas de la cadena de producción y consumo preestablecida por la industria, para forzarlas a responder al plan de acción de los artistas. Con ello, se pretende interpelar al espectador-usuario, tanto en lo referido al plano afectivo como a sus presupuestos racionales acerca del mundo. Segundo, en cuanto a la práctica artística, uno de los artistas (register) se expone en el interior de un escaparate (Ver figura 2), de esta manera elimina cualquier idea preconcebida acerca de su labor. Junto a este, la actividad producida por el otro (storyteller) -la del papel tradicional del cuentacuentos- se basa en traducir y narrar lo que percibimos del mundo. En este proceso, el viandante es, a la vez, espectador y material artístico.

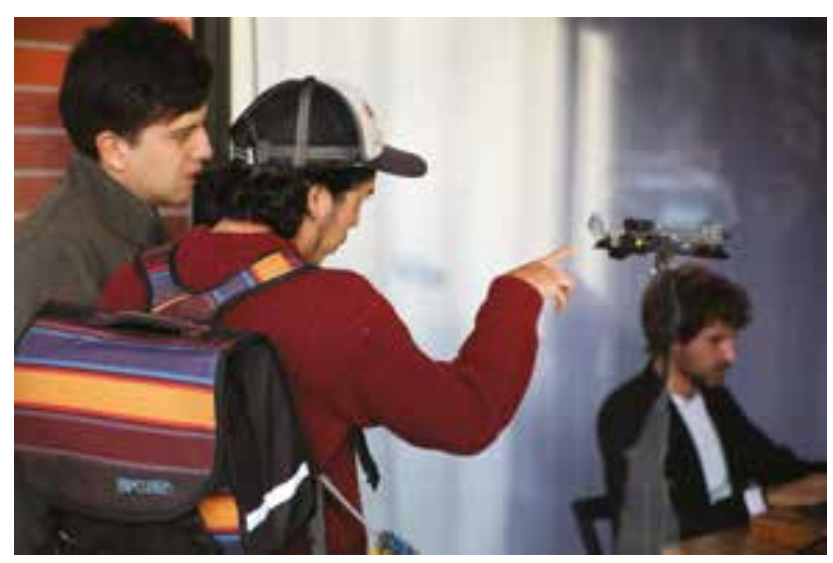

2. Interacción del viandante-espectador con la obra. Fuente: Gabriela Rivadeneira.

Así, el presente texto viene a aportar un elemento más al sistema de realización y activación de la obra, que comenzó en octubre de 2017, con la presentación del trabajo en la Galería + Arte, de Quito, y en el Festival Interactos, de Guayaquil, y continuó con la publicación del libro Register ${ }^{1}$, una compilación de textos teóricos que parten del proyecto en cuestión.

Los investigadores participantes en el libro fueron: 
- Gabriela Rivadeneira, artista investigadora y directora de la Unidad Transversal de Teorías Críticas y Prácticas Experimentales de la Universidad de las Artes (Guayaquil, Ecuador), que, en su texto "Profanar para crear. El arte y sus contradispositivos", nos propone una lectura acerca de las técnicas y los dispositivos, en relación con la responsabilidad del artista de subvertirlos y transformarlos en contra-dispositivos.

- Rubén Tortosa, artista investigador y subdirector de Investigación y Posgrado de la Facultad de Bellas Artes de la Universitat Politècnica de València, quien en su texto "Traslaciones y Transcodificaciones. La imagen creada desde la información", nos acerca a una constante migración de códigos, signos y maneras de producir la imagen, a partir, principalmente, del data.

- José Antonio Figueroa, antropólogo e investigador de la Universidad Central del Ecuador, quien señala la inestabilidad del rol del artista, del espectador y de la obra en la creación artística. "En Register: inquietudes de la cultura en la era digital", cuestionar la supuesta horizontalidad en las relaciones sociales de la condición cultural contemporánea, la cual esconde la injerencia de las corporaciones en la construcción de una subjetividad destinada al consumo.

- Christian Viteri, director de la Carrera de Artes Plásticas de la Facultad de Artes de la Universidad Central del Ecuador, realiza un análisis de Register, presentándolo como un conjunto sistemático de dispositivos de proyección y exhibición que permiten el accionamiento entre el hacer y el contemplar. En su texto "Register: una arquitectura de la mirada" se producen interacciones en un conjunto de relaciones constructivas: las imágenes y la acción directa se entremezclan en lazos sensomotrices.

Adicionalmente, el libro se ha presentado en la Universidad Central del Ecuador y en la Universidad de la República (Uruguay).

Como docentes, artistas e investigadores consideramos importante mostrar tanto nuestra labor artística como lo que se dice de la obra. En este sentido, es importante emplear diferentes canales de activación como el presente, con el fin de que la obra continúe en un constante proceso de construcción.

\section{INSTALACIÓN ARTÍSTICA}

El espacio está dividido en tres zonas: A, B y C (Ver figura 3). En la zona A, uno de los artistas (register) se encuentra sentado ante su computadora en el interior del escaparate de una galería. Tras él, una webcam registra, en tiempo real, lo que sucede dentro y fuera del espacio. El viandante, situado en el exterior (la calle), es registrado por un dispositivo Kinect manipulado, que se aloja sobre el cristal del escaparate. Este sistema registra, mediante clips de vídeo, el retrato del viandante de cuatro modos: registro-webcam, registro-posterizado, registro-3D y registro-data. Este artista, que permanece en su lugar de trabajo en todo momento mientras dura la muestra, únicamente gestiona los registros del dispositivo y los envía al proyector, de manera azarosa, instalado en el interior de la galería.

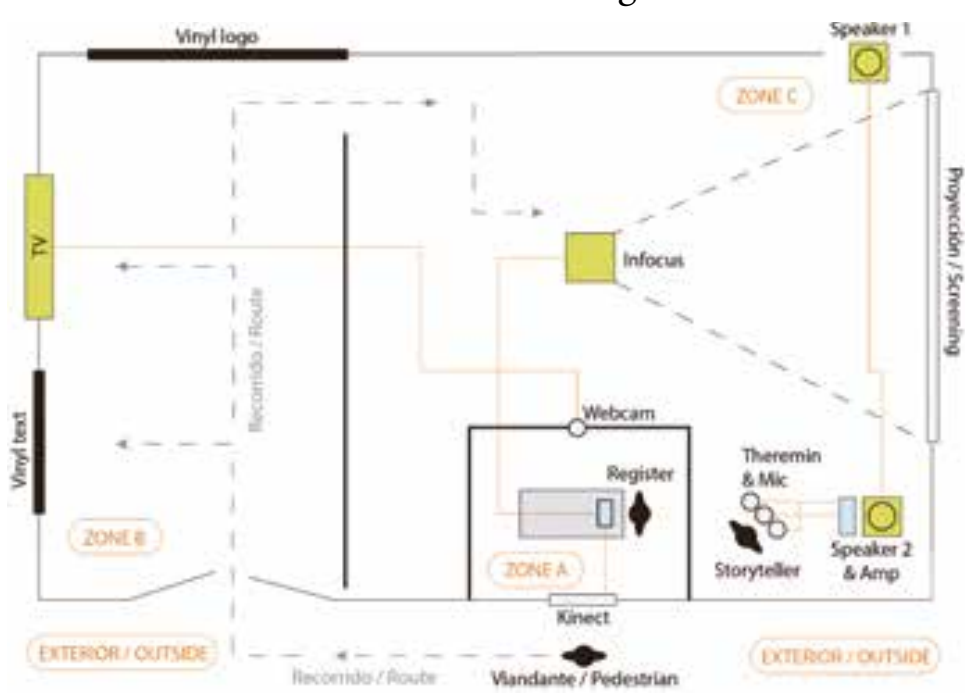

3. Plano de la instalación.

Fuente: Gabriela Rivadeneira.

En la zona B, primer espacio de acceso a la galería, se encuentra una televisión que emite en circuito cerrado y en blanco y negro el registro en tiempo real recogido por la webcam. En la zona C, se dispone tanto la proyección cuatríptica de los registros de los viandantes, efectuados por el dispositivo Kinect, modificados mediante ralentización o bullet time, como el otro artista (storyteller), quien mientras produce sonidos con el movimiento de sus manos, a través del theremin digital, construido específicamente para el presente proyecto, narra una serie de relatos, como por ejemplo:

Hoy recogió el último de sus cabellos. Estaba seguro. Se había cerciorado de que en su cama no quedase ni uno solo. Lo encontró en el baño, dos semanas después. Había resistido a todas la limpiezas. Lo recogió, 
De la exuberancia de la vida, Register sustrae la imagen del viandante, la cual atraviesa por un marco de reglas pre establecidas en el dispositivo-máquina, devolviéndola proyectada cuatripartitamente al mismo viandante, convertido ya en espectador, usuario y material artístico. Los registros de la máquina, aquí, son simulacros fragmentados que van desde el código binario al lenguaje visual. Esta sustracción elimina toda la riqueza personal del espectador (sus gustos, su pasado, su forma de vida, todo aquello que lo constituye como sujeto). La imagen proyectada sufre una serie de alteraciones: en primera instancia, es el dispositivo de registro Kinect el que efectúa los primeros simulacros (blanco y negro, división de la pantalla, diferentes clips relativos al sujeto, etc.) y, en segunda instancia, son alterados por el sonido del otro dispositivo y por las narraciones fuera de campo del storyteller (Ver figura 4). En este aspecto, encontramos una discontinuidad entre la unidad orgánica de la calle y el producto audiovisual.

En Register no existe un itinerario geográfico preestablecido. Los elementos se disponen a lo largo de diversos espacios. Así, este trayecto se ve modificado in situ sobre base de los continuos encuentros del espectador con los diferentes elementos que conforman el espacio instalativo. El encuentro en términos de shock traumático (Zizek, 2008), aquel que requiere de sujetos diferentes, ideas diferentes, materiales diferentes, etc., es un acontecimiento que tiene consecuencias y que puede ser identificado por los efectos producidos en el interior del espacio donde ha ocurrido. Como espectadores, en primera instancia, no solemos poseer la capacidad de asimilar la obra en su totalidad, lo que nos invita a luchar con las nociones y presupuestos previamente aprehendidos del arte para poder realizar interpretaciones acerca de la obra (Portilla, 2015). En este sentido, en Register, el encuentro más significativo ocurre cuando el espectador se encuentra con su imagen proyectada a gran escala en la zona $\mathrm{C}$ de la sala. Es aquí donde la totalidad de la pieza, en términos materiales y técnicos, se devela. La interpretación, en términos conceptuales y afectivos, queda abierta, por lo que la discontinuidad perseguida como objetivo se mantiene. (Ver figura 5). Register es un proyecto de media art indefinido, pues se encuentra a medio camino entre la instalación y el performance, entre el videoarte y el arte sonoro. Esto se debe a las diferentes transformaciones operadas: el espacio de la galería se subdivide, la luz se atenúa, el sonido genera un ambiente de extrañeza, la voz del storyteller irrumpe el espacio ambiental, la proyección a gran escala y mediante los efectos incorporados que magnifican los registros, etc. Existe así, un fenómeno de exceso en esta obra, una suerte de exceso al discurso dominante, algo que desborda el sentido de lo que se denomina arte, pues solo así ocurre lo nuevo.

La conjugación de la totalidad de métodos, herramientas y técnicas empleadas, ha generado una obra que requiere del desplazamiento corporal del viandante y de su participación e inversión subjetiva para completar la pieza.

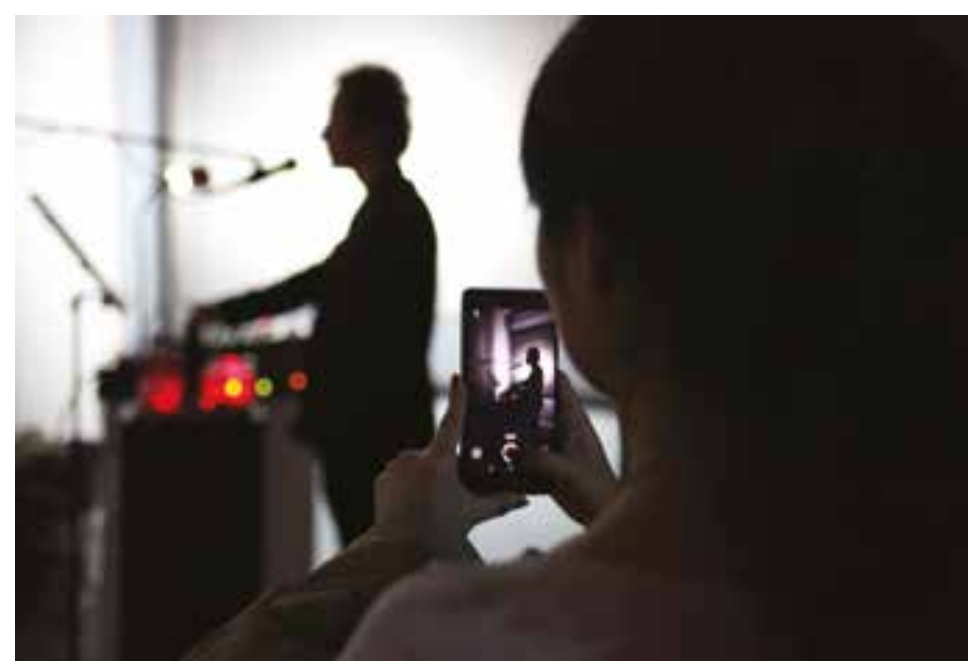

5. La actuación del storyteller registrada mediante un dispositivo intermediario.

Fuente: Gabriela Rivadeneira.

\section{CONCLUSIONES}

En Register se han utilizado diversas herramientas que provienen del lenguaje visual, de las nuevas tecnologías de registro y de la filosofía, al servicio de una obra interdisciplinar, que aborda la discontinuidad entre el mundo real y el lenguaje simbólico. Una experiencia estética múltiple a través del lenguaje visual, del lenguaje sonoro y del desplazamiento corporal.

Las tecnologías empleadas han cumplido la función específica para la cual fueron diseñadas, participando de manera esencial en la consecución del objetivo de la obra. El hecho de que hayan sido herramientas tecnológicas de carácter libres y abiertas (tanto el hardware como el software), ha abaratado significativamente los costes, ha permitido la exposición interna del hardware ante el espectador como estrategia contraria a la ocultación -propia de la industria tecnológica-, y ha hecho posible la adaptación total de estas herramientas a los requerimientos conceptuales del proyecto. 
Register es un encuentro, pues el espectador no tiene, en primera instancia, todos los elementos a su alcance para digerir y comprender la obra en su totalidad. Así, requiere del descubrimiento progresivo de los componentes que conforman la obra.

Register porta un exceso, en el sentido de la indefinición género-lingüística del mismo, con respecto a la categorización convencional del arte.

Cabe señalar que la relación histórica que han mantenido la ciencia, la tecnología y el arte, sigue siendo fundamental para perpetrar obras de carácter interdisciplinar. La experiencia concreta en cuanto a las relaciones entre artistas e ingenieros en el desarrollo de este trabajo, se definió por la continua modificación de algunas características de los dispositivos, forzada por límites técnicos. Estos fueron solventados con un diálogo continuo entre ambas partes al servicio del objetivo principal del presente proyecto.

\section{AGRADECIMIENTOS}

Al equipo de diseño, desarrollo y testeo de los dispositivos: Iván Terceros, Daniela Leyton, Andrés Rodríguez, Carlos De Smedt, Juan Pablo Salazar, Carlos Natera y Club de Arduino Medialab UIO. Gracias a Gabriela Moyano (+Arte Galería) y al equipo del Festival Interactos (UArtes, Guayaquil), en especial a Gabriela Rivadeneira Crespo. A Isabel Zarco. A José Ramón Alcalá y al Grupo de Investigación 'Interfaces Culturales Arte y Nuevos Medios'. A José Antonio Perona y a la Editorial Universidad de Castilla-La Mancha.

\section{BIBLIOGRAFÍA}

Badiou, A. (2015). Prefacio, en S. Zizek, Moins que rien. Hegel et l'ombre du materialismo dialectique. París, Francia: Fayard.

Eco, U. (1986). Apostillas a El nombre de la rosa. Buenos Aires, Argentina: Lumen.

Hegel, G. W. F. (2017). Fenomenología del espiritu [1807]. México, México D.F: FCE.

Jameson, J. (2009). Valences of the Dialectic. Londres, Inglaterra: Verso.

Jameson, J. (2008). “The Vanishing Mediator, or, Max Weber as a Storyteller" [1979], en The ideologies of Theory, Londres, Inglaterra: Verso, pp. 309-341.

Portilla, C. A. \& Ruiz Martín, J. M. (2017). Register. Cuenca: Editorial UCLM - Colección Caleidoscopio.
Portilla, C. A. (2015). L'artiste en tant que sujet politique. Dexu exemples: William Burroughs et Cildo Meireles. Trois ouvres: Last Words, Insertions dans les circuits idéologiques et Le sermon sur la montagne: Fiat Lux. (Tesis doctoral.) Université Paris 8, Paris, Francia.

Ruiz Martín, J. M. (2014). Aparición, impacto y efectos de la máquina automática en el atelier del artista. Del taller tradicional al medialab. (Tesis Doctoral). Universidad de Castilla-La Mancha, Cuenca, España.

Zizek, S. (2012). Less Than Nothing. Hegel and the Shadow of Dialectical Materialism. Londres, Inglaterra: Verso.

Zizek, S. (2008). Organes sans corps. Deleuze et conséquences. París, Francia: Editions Amsterdam. 